\title{
Integrating Life Cycle Costing (LCC) and Life Cycle Assessment (LCA) Model for Selection of Centralized Chilled Water Generation - Review Paper
}

\author{
Ali Akbar ${ }^{1}$ and Ainul Akmar Binti Mokhtar ${ }^{2}$ \\ ${ }^{12}$ Mechanical Engineering Department, Universiti Teknologi PETRONAS, Bander Seri Iskandar, \\ Perak, Malaysia
}

\begin{abstract}
This paper presents a review of literature relating to Life Cycle Costing (LCC) and Life Cycle Assessments (LCA) in Gas District Cooling plant. The gas district cooling plant uses either vapour compression process or absorption process for the chilled water generation. Both processes have impacts on the economic aspects as well as the contribution to $\mathrm{CO}_{2}$ emissions; thus, integration of the cost and environmental analysis of both processes are necessary. An extensive body of literature exists on both subjects, however, there is very limited number of available literature on the integration of LCC and LCA. The purpose of this review is to find the most suitable optimization model which can integrate the LCC and LCA to provide the best decision in choosing the most cost-effective and environment-friendly system. This review assesses the literature from thirtyfour journals, research papers, and case reports from the year 1995 to 2017. The result of this review shows that the goal programming methodology is the appropriate method for integrating LCC and LCA because it provides the optimal decision in choosing the most cost-effective, environmentfriendly system for the chilled water generation.
\end{abstract}

\section{Introduction}

PETRONAS, the national oil corporation of Malaysia created the terminology Gas District Cooling (GDC). PETRONAS originally co-owned the plants. It is a cogeneration plant system that produces chilled water and electrical power simultaneously. Majid et al. [1] highlighted the various systems around the world which have a resemblance to GDC but they are known as district cooling, district heating, and district energy, it depends on the nature of their operations of which some do not produce electricity. Adzuieen et al.[2] discussed that the natural gas is used as the fuel for gas turbines for the GDC system, which generates electricity. The waste heat from the turbine outlet is used as the primary energy source in steam absorption chillers to produce cooling water for air-conditioning systems. Here, the heat is used to vaporize the cooling-liquid solution in the generator of steam absorption chillers. The free heat or energy from the turbine outlets is utilized by such an integrated energy system, which would otherwise be released to the environment and wasted [3]. Since GDC uses mainly the steam absorption chiller, which uses only water and lithium bromide 
so the environment is better protected with the use of GDC system [4]. The usage electric chillers, which use refrigerants such as R134a, are minimized in GDC plants, whereas in conventional systems, these chillers are the primary equipment used for generation of chilled water [5].

Gilani et al. $[6,7]$ indicated that most of the GDC plants used vapor compression and absorption processes for chilled water generation. These processes differ in terms of the source of energy, operation, and heat emission. Since these processes play an important role in enhancing the efficiency of the GDC plant but also contributes to $\mathrm{CO}_{2}$ emissions to the environment. Many analyses have been done by different authors on gas district cooling (GDC) plant at University Teknologi PETRONAS (UTP) covering life cycle costing (LCC) of chilled water generation. However, there is no any integrative study was done which can integrate and simultaneously assess the cost and $\mathrm{CO}_{2}$ emission of both the processes used in chilled water generation at GDC-UTP. So the purpose of this review is to find the most suitable optimization model which can integrate the LCC and LCA simultaneously to provide the best decision in choosing the most cost-effective and environment-friendly system for chilled water generation.

This review will assess the literature from maximum possible journals, research papers, and case reports available from the previous years. This review is initiated by categorizing the literature based on the year of publication, followed by the categorization based on the methodology used by literature review. Some of the categories were used to classify the LCC, some are in LCA, and the others are in the integration of LCC and LCA.

The next step is to decide how to collect the material and to choose the case studies suitable for the review. After that, the articles chosen will be classified according to the different categories on LCC, LCA and on their integration also.

Based on our literature review, the literature in the field of life cycle costing and life cycle assessment was quite fragmented. Therefore, we decided to use several databases instead of individual journals to identify LCC case studies. The databases were chosen according to our access to different databases. Due to the contents of these databases in Google Scholar, it was not possible to define article sections to narrow down the search, so we decided to limit the search only to article title.

\subsection{Life Cycle Costing (LCC)}

Life Cycle Costing (LCC) evolved in the 1960s, during the development of United States Department of Defense to enhance their cost-effectiveness [8]. Burhani et al. [9] emphasized that the LCC is the summation of costs estimates associated with the total product life cycle activities. It attempts to identify the best value for investment consumption (i.e. the lowest long-term cost that addresses the required performance) [4].

In these days, LCC is used widely in industries as decision-making tools or as management tools [10]. The analyst should assure that the level of details integrated into LCC is sound with the level of investment decision under consideration. There comes a point of diminishing returns as more and more cost factors are incorporated into LCC [11]. As Sullivan et al. [12] discussed the relative influence of individual factors on the LCC analysis results may change from primary to minor to inconsequential. For example, minor differences in future costs have a significant effect on discounted present value. Including such factors as this will complicate the analysis without producing actual improvement in analysis outcomes. Including all factors in every analysis is frequently not progressive [13]. In conducting an LCC, analysts should investigate all aspects of inclusion and clarify the motive for eliminating factors [14]. In simple terms, LCC is an analysis technique that guides to better investment outcomes [15]. 


\subsection{Life Cycle Assessment (LCA)}

Yusnee et al. [16] and Yang et al. [17] stress that the life cycle assessment (LCA) is the investigation and evaluation of the environmental impacts of a given product or service. The main objective of LCA is to identify and improve the environmental effects and aspects of products at various points in their life cycle. It is an integrative tool for the quantitative evaluation of the environmental impacts of a product or service system through all phases of its life. LCA takes a whole life cycle, from the initial stage to the disposal stage of any product/equipment. In industry, LCA is typically used for the design or improvement of products and processes [18]. This may involve identifying environmental hotspots in production processes as well as considering upstream or downstream processes such as energy sources, product additives, end-of-life management options or by-products consumed in the product use phase [19]. LCA results can also be used as part of the environmental management system to prove continuous improvement or to provide information for ecolabeling or environmental rating schemes [20]. LCA quantifies whether a product is environmentally friendly or not. In another way, LCA qualifies which product is greener [21]. LCA analyzes the life cycle of a product in environmental terms on the basis of emission released and consumption of raw materials. This actually can support future decision-making.

\subsection{Combining Life Cycle Costing And Life Cycle Assessment}

When combining economic and ecological dimensions to GDC, they can be alleged to balance each other in overall development. Lower energy utilization equals lower running costs [22]. The existing literature presents some examples of connecting the economic and ecological dimensions of life cycles. Attempted in bringing together the economic LCC with the environmental LCA was shown in the case of municipal waste management systems [23]. Heijungs et al. [24] introduced a common unit to measure both total costing and environmental impacts. However this technique enabled the analysis, but issues of rational methodology between economic assessments and environmental assessments remained same. Junnila et al. [20, 25] presented a method of calculating the economic and environmental life cycle costs in one assessment model and also proposed another method in which LCA and LCC were combined together to address the life cycle green costs of buildings. A life cycle management approach was proposed in this study for large-scale development resorts, where LCC and LCA were linked together in order to create designs that provide environmental sustainability with low operational costs [26]. This study combines LCC and LCA in a case of GDC plant, aiming to classify the actual technologies that could elaborate the maximum sustainable viability and assess the emissions and correspondent mitigation potentials associated with the different technologies [27].

Considering a life cycle perspective can support sustainable decision-making, with LCC and LCA being the leading tools for addressing economic and environmental burdens, respectively [28].

\subsection{Multi-Objective Goal Programming}

Due to the presence of two or more conflicting objectives at the same time, it is often impossible to model the problem as a single-objective programming problem [29]. To overcome this problem the need to use the Multi-objective goal programming approach cannot be neglected. Multi-objective goal programming (also known as a multi-objective optimization) is an area of multiple criteria decision making, that is concerned with mathematical optimization problems involving more than one objective function to be optimized simultaneously [30]. The concept of multi-objective optimization was originally 
defined by [31]. Since then, it has experienced enormous progress and has been successfully applied in different fields of science. Jones et al. [32] developed a multi-objective model by using goal programming methodology for dynamic cell formation problem. The first objective function of the developed model seeks to minimize total cost of machine procurement, machine relocation, inter-cell moves, overtime utilization, worker hiring/laying-off, and worker moves between cells; while the second objective function maximizes labor utilization of the cellular manufacturing system. As in 2016, Shao et al. [33] addressed the problem of representing the continuous but non-convex set of non-dominated points of a multi-objective linear programming by a finite subset of points. Thus it is recommended that a multi-objective linear programming is also required for GDC-UTP which will integrate the LCC and LCA and will be helpful to provide the best decision among choosing the most economical and environment-friendly system for chilled water generation

\subsection{Conclusion and Overview}

The purpose of this study is to examine both the environmental and economic life cycle results in order to add valuable information for decision-makers and future researchers. Despite the similarity of their names, LCC and LCA have major methodological differences. It is found that the process scope of the LCC includes only those processes imposing direct economic costs (or benefits) upon the decision maker. As in an LCA, we might neglect costs which are expected to be equivalent among alternatives. The LCC takes careful account of the timing of the cost flows, while LCA neglects flow timing. The LCC includes cost risks, and how they are altered or avoided as a function of product/process design investment options, but the LCA considers flows of pollutants and resources from each of the modeled processes.

However, this study combines LCC and LCA, aiming to clarify the decision situation which decides the suitability of the process or equipment and to classify the actual technologies that could elaborate the maximum sustainable viability. Whereas, findings in literature review indicated that the Goal programming approach can support sustainable decision-making, by integrating the LCC and LCA. Furthermore, the goal programming approach will also help to develop criteria for selecting the most cost-effective and environment-friendly system for chilled water generation.

\section{References}

1. A. Majid and M. Amin, (2011).

2. N. Adzuieen, M. Amin and A. Majid, (2013).

3. A. Nordin, N. Buyamin, M. A. A. Majid and S. A. S. Ariffin, Int. J. Comp. Elec. Eng. 5 (3), 284 (2013).

4. S. Amear, S. Ariffin, A. Nordin, N. Buyamin, M. Amin and A. Majid, Asian J. Sci. Res. 6 (2), 299 (2013).

5. M. A. A. Majid, S. A. Sulaiman, I. Ibrahim and Z. Baharddin, J. Appl. Sci. 12 (24), 2636 (2012).

6. S. Gilani, M. Amin and C. Rangkuti, Dist. Energy 94 (3), 14-18 (2008).

7. S. I.-u.-H. Gilani, M. A. A. Majid and C. Rangkuti, (2006).

8. M. J. Epstein, Report No. 0786302305, 1996.

9. N. R. A. Burhani, A. Majid and M. Amin, (2012).

10. P. Gluch and H. Baumann, Build. Environ. 39 (5), $571-580$ (2004). 
11. S. J. Kirk and A. J. Dell'Isola, LCC. Design. Prof. (1995).

12. W. G. Sullivan, E. M. Wicks and C. P. Koelling, (Singapore. Prentice Hall, Inc, 2012).

13. R. Flanagan, G. Norman, J. Meadows and G. Robinson, Practice. BSP Professional Books, Oxford (1989).

14. Y. Qian, Z. Huang and Y. Jiang, Chem. Ind. Eng. Progress 25 (2), 126 (2006).

15. D. Langdon, Literature Review, Davis Langdon Management Consulting (2007).

16. N. I. B. M. Yusnee, 2010.

17. D. Yang, L. Fan, F. Shi, Q. Liu and Y. Wang, Resources, Conserv. Recycl. (2016).

18. E. Martínez, F. Sanz, S. Pellegrini, E. Jiménez and J. Blanco, Renew. Energy 34 (3), 667-673 (2009).

19. H. W. Kua and S. Kamath, J. Clean Prd 81, 190-200 (2014).

20. S. Junnila, A. Horvath and A. A. Guggemos, J. Infrastruct. Syst. 12 (1), 10-17 (2006).

21. S. Xing, Z. Xu and G. Jun, Energy Build. 40 (7), 1188-1193 (2008).

22. T. Nauclér and P.-A. Enkvist, McKinsey \& Company 192 (2009).

23. M. C. Reich, J. Clean Prd 13 (3), 253-263 (2005).

24. R. Heijungs, E. Settanni and J. Guinée, Int. J. LCA 18 (9), 1722-1733 (2013).

25. S. Junnila, Int. J. LCA 13 (5), 432 (2008).

26. K. L. Brown, D. C. Greer and B. Schwegler, in Towards Life Cycle Sustainability Management (Springer, 2011), pp. 229-238.

27. M. Ristimäki, A. Säynäjoki, J. Heinonen and S. Junnila, Energy 63, 168-179 (2013).

28. R. Kannan, C. Tso, R. Osman and H. Ho, Energy Convers. Manage. 45 (18), 3093-3107 (2004).

29. J. Razmi, E. Jafarian and S. H. Amin, Exp. Sys. Applic. 65, 181-193 (2016).

30. C.-L. Hwang and A. S. M. Masud, Multi. Obj. dec. mak. Method. Applic. (Springer Science \& Business Media, 2012).

31. S. Mirjalili, S. Saremi, S. M. Mirjalili and L. d. S. Coelho, Exp. Sys Applic. 47, 106-119 (2016).

32. D. Jones, H. Florentino, D. Cantane and R. Oliveira, Eur. J. O.R. 255 (3), 845-855 (2016).

33. L. Shao and M. Ehrgott, Eur. J. O.R. (2016). 